\title{
Eğitimde Performans Artırmaya Yönelik Yeni Paradigmalar: Kısıtlar Kuramı Bağlamında Bir Değerlendirme
}

\author{
DOI: $10.26466 /$ opus. 969781
}

$*$

\author{
Ercan Baysülen * - Şefika Şule Erçetin ** \\ * Yönetici, MEB, İzmir/Türkiye \\ E-Posta: ebaysulen@gmail.com \\ ORCID: $\quad$ 0000-0002-4695-5123 \\ ** Prof.Dr., Hacettepe Üniversitesi, Eğitim Yönetimi, Ankara/Türkiye \\ E-Posta: ssule@hacettepe.edu.tr \\ ORCID: $\quad \underline{0000-0002-7686-4863}$
}

\section{Öz}

Okullarda oluşturulan programların gücünde ve başarısında performans çalışmaları önemli yer tutar. Bu çalışmada Türk Milli Ĕ̆itim Sistemi özelinde performans artırmaya yönelik yapılmış çalışmalar incelenmiş bu bağlamda okulların eğitim kalitesini ve performansinı artırma noktasında Kısıtlar Kuramı'nın uygulanabilirliği değgerlendirilmiştir. Bu kuram, sistemi zincirin halkalarına benzetir. Sistemin gücünün en zayıf halka kadar olduğunu düşünür. Sistemdeki en zayıf halkaya yapılacak iyileştirmenin aslında sistemin tamamının iyileştirilmesi yani performansının artırılması olacağını kabul eder. Başka bir deyişle bu kuram, yöneticiyi sistemdeki performansı olumsuz etkileyen en zayıf halkaya odaklanması açısından yönlendirir. TKY'nin okullarda kaldırılmasından sonra okullarımızda yöneticiye okulun performansının nasıl arttırllacağına yönelik sistemli bir yöntem sunulmamıştır. Bu yöntemsizlik her okulda, okul yöneticisi tarafindan performansa yönelik farklı uygulamalar yapmasina neden olmuştur. Yanlış uygulamaların zaman ve emek kaybı olmasından öte toplumsal gelecek açısından da farklı olumsuz sonuçları olabilecektir. Çalışmada, daha önce eğitim alanında yapılmış performans çalışmaları ışı̆̆ında Kısıtlar Kuramı'nın ortaya koyduğu ilkelerin eğitimde performans geliştirmeye yönelik yeni paradigmaların oluşturulmasına katkı să̆layacă̆ı düşüncesi ortaya konulmuştur.

Anahtar Kelimeler: Eğitim, Performans, Performans Yönetimi, Kısıtlar Kuramı, Eğitim Yönetimi. 


\title{
New Paradigms for Improving Performance in Education: An Evaluation in the Context of the Theory of Constraints
}

\begin{abstract}
Performance studies have an important place in the power and success of the programs created in schools. In this study, studies on improving performance in the Turkish National Education System were examined and in this context, the applicability of the Theory of Constraints was evaluated in terms of increasing the education quality and performance of schools. This theory likens the system to the links of the chain. He thinks that the strength of the system is only the weakest link. It accepts that the improvement to be made to the weakest link in the system will actually be the improvement of the entire system, that is, the increase of its performance. In other words, this theory guides the manager in terms of focusing on the weakest link that affects the performance in the system. After TQM was abolished in schools, no systematic method was presented to the administrators in our schools on how to increase the performance of the school. This lack of method has led to different performance-oriented practices by the school administrator in each school. Besides being a waste of time and effort, wrong practices may have different negative consequences for the social future. In the light of previous performance studies in the field of education, the study is thought to contribute to the creation of new paradigms for improving performance in education, based on the principles of the Theory of Constraints.
\end{abstract}

Keywords: Education, Performance, Performance Management, Theory of Constraints, Educational Administration. 


\section{Giriş}

İnsan, doğası gereği öğrenmeye ve eğitilmeye yatkın ve bunu çok iyi başarabilecek bilişsel ve duyuşsal yeteneklere sahip bir varlıktır. Dolayısıyla insan, hayatında kaydettiği bilgileri, yöntemsel hale getirmek ve bu ürünleri nesilden nesile aktarmak için çok önemli iki şeye ihtiyaç duymuştur: Bunlardan biri eğitim, diğeri ise sistemsel olarak bunları aktarabileceği mekanlar olan okullardır. Fidan ve Erden (1998), eğitimi; bireylerin toplumun standart, inanç ve yaşama yollarını kazanması açısından etkiye sahip tüm sosyal süreçleri de kapsayan, bireyin toplum açısından değere sahip yetenek, tutum ve diğer davranış biçimlerini geliştirdiği süreçlerin tümü olarak ifade etmişlerdir. Söze devamla eğitim, bir toplumun değerlerinin, varlığının ve bilgi birikiminin aktarılması; bireyin ruhsal ve bedensel gelişimi olarak düşünülebilir. $\mathrm{Bu}$ anlamda, sosyal bilimciler ise eğitimi sosyalleşme veya kültürleşme olarak ifade etmişlerdir. Yani bireylerin yetişkinlik tarzına göre toplumdaki nihai rollerini üstlenebilmelerine rehberlik etmek için oluşturulmuş sistemli tasarım, şeklinde kabul edilebilir. Bu tasarımın kurulu bir düzeneği olan okullar da toplum tarafından kendisine verilen görevi yapmaya çalışırlar.

Toplumlar giderek daha karmaşık hale geldikçe ve okullar giderek daha kurumsallaştıkça, eğitim deneyimi günlük yaşamla ve okullarla daha girift hale gelmiştir. Resmi bir atmosferdeki bu öğrenme deneyimi, çocukların yalnızca gözlemleyerek, taklit ederek veya ezberleyerek öğrenebileceklerinden çok daha fazlasıdır. Bu anlayış, toplumun giderek eğitime daha fazla önem vermesine dolayssıyla eğitimin genel amaçlarının, içeriğinin, organizasyonunun ve stratejilerinin yeniden formüle edilmesine vesile olmuştur. Bu yöntemlerin toplumların eğitim amaçları ve o toplumun eğitim felsefesi doğrultusunda oluşturulduğu söylenebilir. Netice olarak eğitim üzerine aynı zamanda "felsefî bakış tarzi"yla da düşünmek bir zorunluluk olarak görünmektedir (Bircan, 2018).

Toplumların eğitim felsefesi, toplumun yetiştirmek istediği insan tipini ve oluşturmak istediği toplum tasarımını ifade etmektedir. Bu ifade doğrultusunda günümüz koşulları, bireyin ve toplumun talepleri ile beklentileri de göz önünde bulundurularak okullarda performans 
artırmaya yönelik yeni yeni fikirlere, farklı paradigmalara ihtiyaç duyulduğu söylenebilir. Buradan hareketle, Kısıtlar Kuramı bağlamında eğitim kurumlarında performansın nasıl arttırılacağına yönelik bir araştırma yapılması önemli görülmektedir. Özetle Kısıtlar Kuramını temele alan bir eğitim uygulamasının analiz edilmesinin alana katkı sağlayacağı düşünülmektedir.

Çalışmanın amacı okullarda eğitim kalitesinin ve performansının öneminden hareketle Kısıtlar Kuramı'nın ortaya koyduğu ilkeler çerçevesinde bu kuramın eğitime sağlayabileceği katkıları açısından analiz etmektir. Araştırmanın bu temel amacı çerçevesinde Kısıtlar Kuramı'nın ilkelerinin eğitimde uygulanabilirliği yönünden değerlendirme yapılacaktır.

\section{Eğitimin Amaçlarını Gerçekleştirmesi Açısından Okulun Önemi}

Eğitim, belirli amaçlara sahip bir girişimdir ve bu amaçlar ülkelerin yönetim ve eğitim felsefelerine göre değişiklik göstermektedir. Türkiye Cumhuriyeti Devleti'nin eğitim amaçları, 1739 Sayılı Milli Eğitim Temel Kanununda genel ve özel amaçlar olmak üzere iki başlık altında ifade edilmiştir. Genel amaçlar iyi yurttaş, akıllı tüketici olmak gibi soyut kavramları kapsarken özel amaçlar her okul kademesinde öğrencilere kazandırılması öngörülen bilgi, beceri, tutum ve davranışları kapsar.

Okul, eğitimin amaçlarını gerçekleştirmesi beklenen bireylerin işleri ve birbirleriyle olan etkileşim biçimleri tarafından nitelenmiş olan toplumsal sistemdir (Aydoğan ve Pehlivan, 2002). Bu toplumsal sistemin yapısı eğitim denilen sürecin işleyişini ve niteliğini belirlediğinden okul örgütlerinin yapısı toplumsal yapıdaki değişmelerle birlikte üzerinde sıkça durulan bir konu olmuştur. Eğitim ve okul başka hiçbir sektörde görülmeyecek ölçüde ve sayıda kişi ile kurumun ilgi alanındadır. Başta kamu, din, siyaset, iş dünyası, toplum ve sivil kuruluşlar olmak üzere birçok kurum eğitimle yakından ilgilenerek onu kendi bakış açıları ve gereksinimleri doğrultusunda etkileyip yönlendirmeyi amaçlar. Erdoğan (2000), bu amacın temelinde eğitim ve okulların, bu kurumların ihtiyacı olan insan gücünü, bilgi, beceri ve değerleri üreten bir sistem olmasının yattığını ifade etmiştir. Balcı (1993), bir eğitim örgütü olarak okulu eğitim sisteminin amaç ve ilkeleri doğrultusunda öğrencilere bilgi, beceri 
ve davranışların kazandırıldığı yer, şeklinde ifade etmiştir. Eğitim hizmetinin üretilip sunulduğu yer olan okulu bir örgüt olarak ele almak gerekirse onu bir hizmet örgütü olarak nitelendirmek mümkündür. Lakin okulun girdiler, işleme süreçleri, sonuç ve çıktıları açısından diğer örgütlerden farklı olduğu ifade edilebilir (Şişman ve Turan, 2004). Okullar, kitlesel eğitimin yapıldığı yerler olarak modernleşme ve sanayileşme süreciyle birlikte gelişmeye başlamıştır. Bu süreçte okulların iş bölümü ve uzmanlaşmaya bağlı, hayattaki çeşitli rol ve uzmanlık alanlarına ayrılan yerler biçiminde görüldüğü bilinmektedir (Şişman ve Taşdemir, 2008). Bu dönemde okullar, bir fabrika gibi değerlendirilmiş ve bir işletme mantığıyla ele alınmıştır.

\section{Eğitimde Performans ve Eğitimi Etkileyen Etmenler}

Erşangur (2003), performansı, bir kişinin sahip olduğu potansiyeli ya da gerçek bilgi, yetenek ve kabiliyetlerini hedef ve beklentilere ulaşabilme amacıyla ne ölçüde kullanabildiğini tanımlayan bir kavram olarak, ifade etmiştir. Diğer bir deyişle performans, insanın sahip olduğu kapasiteyi; bir işi belli zaman dilimi içinde başarıyla tamamlamada kullanabilme yüzdesidir. Buradan yola çıkılarak performansın, bireyin mevcut potansiyelini geliştirme ve kullanmaya ne derece motive olduğuna bağlı olduğu söylenebilir.

Dünyada son yıllarda özellikle bilgi ve teknoloji alanındaki gelişmeler diğer alanları da doğrudan etkilemiştir. Değişimden en çok etkilenen alanlardan biri de eğitimdir. Eğitim kurumları, değişen çağa ayak uydurmak adına yeni anlayış ve gelişmeleri takip etme ihtiyacı duymaktadır. Eğitimde uygulanan geleneksel ve ezbere dayalı öğrenmenin yerini yapılandırmacı, uygulamalı ve proje merkezli yaklaşımlar almıştır (Teyfur, 2010). Eğitimin kalitesini, performansını ve niteliğini artırmak açısından en önemli etmenin öğretmenler olduğu söylenebilir. Öğretmenler; eğitim sistemlerinin vazgeçilmez unsurlarından biri şeklinde kabul görmüş; nitelikli öğretmen yetiştirme konusu ise eğitim sistemi reformlarının ve başarının önemli bir yönünü oluşturmuştur (Taşgın ve Sönmez, 2013). Aslında eğitim ve öğretim faaliyetinin gerçekleştirilmesinde sistemdeki tüm etmenler büyük öneme sahiptir. Ancak öğretmen; eğitim ortamının düzenlenmesinde, eğitimin 
gerçekleşmesindeki öğeler arasında eşgüdümün sağlanmasında, uygun öğretim metotlarının seçiminde, insan ilişkilerinde başarılı olmak ve öğrencileri öğrenmeye motive etmek gibi önemli görevler üstlenir. Bu sebeple öğretmen rolünün eğitim amaçlarının gerçekleştirilmesinde en stratejik ve önemli rol olduğu söylenebilir (Taşgın ve Sönmez, 2013).

Eğitimci John Dewey, 1939'da eğitimde performansın artırılmasına yönelik hazırlamış olduğu raporda Türk okullarının amaç ve hedeflerinin belirlenmesinin eğitimde dikkat edilmesi gereken ilk ve en önemli unsur olduğunu ifade etmiştir. Dewey (1939), istenen tedbirlerin açığa kavuşmasının ve mükemmel bir program hazırlamanın ancak okulların amaç ve hedeflerinin belirlenmesiyle mümkün olduğunu belirtmiştir. Okulların amacı kesin ve açık olursa birtakım gereksiz değişikliklerden ve sözde düzeltme adına yapılacak etkisiz önlemlerden okullar korunmuş olunur. Amacın olumlu yorumu girişimlere ilham verir, önerilen tedbirler için kontrol ve denetleyici görevi görür ve eğitim alanında alınacak uygun önlemlerin sırasının belirlenmesine yardımcı olur. Ona göre okulun amacı iki yönlüdür. Bir yandan, ulusal faydalar sağlayan bilgi merkezi ve bilgi toplama ve yayınlama aracı olmak; öte yandan, öğrencileri ülkeye faydalı olacak entelektüel kaynaklarla donatmak ve aldıkları bilgiyi teorik ve gereksiz olmaktan kurtarmaktır (Dewey, 1939, s.3,4,5,8).

\section{Türk Milli Eğitim Sisteminde Performans Artırma Çalışmaları}

Cumhuriyetin kuruluşunun ilk 10 yılında eğitim öğretimin iyileştirilmesi adına Tevhidi Tedrisat Kanunu, yeni Türk alfabesinin kabulü gibi pek çok inkılap gerçekleştirilmiştir. Bu dönemde Avrupa'dan J. Dewey, A. Kuhne ve Omar Buyse gibi önemli eğitimciler ülkeye davet edilerek bu uzmanların eğitim sisteminin gelişmesine yönelik önerilerinden yararlanılmış, ülkenin kalkınması amacıyla eğitim sisteminin yeniden yapılandırılması sağlanmıştır. Cumhuriyet döneminde eğitimin temel amacının her düzeydeki okullarda Cumhuriyet rejiminin gerektirdiği ve yeni Türkiye'nin ihtiyaç duyduğu nesiller yetiştirmek olduğu söylenebilir (Akyüz, 2011, s.331). Bu amaç doğrultusunda özellikle Cumhuriyetin ilk yıllarında büyük öneme sahip çalışmalar yapılmıştır. 3 Mart 1924'te kabul edilen Tevhid-i Tedrisat Kanunu ile eğitimin devlet 
kontrolündeki eğitim kurumlarında gerçekleştirilmesi ve öğretimde birliğin sağlanması amaçlanmıştır. Öğretimde birliğin sağlanması amacıyla kabul edilen bu kanun, eğitimde performansı artırmaya yönelik atılmış önemli adımlardan biri kabul edilebilir. 1926 yılından itibaren ortaöğretimde karma eğitime geçilmesi, 1928'de Latin Harflerinin kabulü gibi adımlar da eğitim performansını artırmaya yönelik önemli çalışmalardır. Bu çalışmaların ardından hem yeni alfabenin halk tarafından öğrenilmesi hem de okur-yazar oranının artırılması amacıyla Millet Mektepleri açılmış (Güven, 2018, s. 213), 1926 tarihli ilkokul programında öğrenci öğrenmesini sağlamak amaciyla öğretimde "toplu tedris" ilkesi getirilmiştir (Akyüz, 2011,s. 347).

1939'da I. Eğitim Şurasında tüm köy ilkokullarının öğrenim süresi 5 yıla çıkarılmış, 1940 yılında Köy Enstitüleri kurulmuştur. Köy Enstitüleri ile öğretmen yetiştirme politikasında önemli bir değişikliğe gidildiği ifade edilebilir (Ortaş, 2005). 1973 tarihli Milli Eğitim Temel Kanunu ile ilköğretim 8 yıllık bir süreç olarak düzenlenmiş ve 1981-1982'de deneme şeklinde uygulanmaya başlanmıştır. 1997-1998 öğretim yılına kadar 5 yıllık zorunlu ilkokul eğitimi devam ederken 1997-1998 eğitim öğretim yılında ülke çapında 8 yıllık zorunlu ilköğretim uygulaması başlatılmıştır. 2012-2013 öğretim yılında ise 4+4+4 şeklinde 12 yıllık kesintili eğitime başlanmıştır. 1990 yılında Türkiye Cumhuriyeti Hükümeti ile Dünya Bankası arasında yapılan bir antlaşmayla, Dünya Bankasının kredi desteği ile ülkemizde "Milli Eğitimi Geliştirme Projesi" bünyesinde 208 okulda "Müfredat Laboratuvar Okulları Projesi" uygulamasına geçilmiştir (MEB, 1995, s.46). Böylece dünyada uygulamaya çalışılan ve endüstriden sonra eğitimde de en önemli performans artırma çalışma hareketi olan TKY Türk eğitim sisteminde yer edinmiştir.

Eğitimde performansı artırmaya yönelik önemli yasal metinler arasında kalkınma planları ve Milli Eğitim Şuraları da yer almaktadır. Beşer yıllık periyotlar şeklinde hazırlanan kalkınma planlarının ilki 1963 - 1967 yıllarına yönelik; 11. ve sonuncusu ise 2019-2023 yıllarına yönelik planlanmıştır. Kalkınma planlarında Milli Eğitim hedeflerine yönelik planlamalar da yer almaktadır. Onuncu Kalkınma Planında eğitimde istenilen seviyenin yakalanamaması, Pisa tarafından yapılmış araştırmalarda ortalamanın altında kalınması gibi sebeplerle eğitim 
sisteminde performans geliştirmeye yönelik güçlü olduğu düşünülen bir plan hazırlanmıştır.

Eğitimde performans artırma çalışmasını son olarak 2023 Vizyon Belgesinde görmekteyiz. Eğitim Vizyonu'nun hedefi, ahlak anlayışını temele alıp insanı merkeze konumlandıran bir varlık ve bilgi anlayışına hayat vermek, şeklinde belirlenmiştir. Bu belgede, 2018-2019 eğitim öğretim yılında tasarım, simülasyon ve öncü pilot uygulamaların yapılacağı ve 2019-2020 eğitim öğretim yılında ülke çapında pilot uygulamaların ortaya konulacağı ve tasarımı biten eylemlerin uygulamaya geçirileceği ve 2020-2021 eğitim öğretim yılında ise ana hedefler altında yer alan eylemlerin tümünün hayata geçirileceği ifade edilmiştir (MEB , 2018).

\section{Kisıtlar Kuramı}

Kisitlar Kuramı (KK) (Theory of Constraints - TOC) Dr. Eliyahu Goldratt tarafından 1980'li yıllarda "The Goal" ve "The Race" kitaplarında ortaya atılan ve sistemin darboğazlarını tespit ederek onları giderme anlayışına dayanan yönetim felsefesidir. Kısıtlar Kuramı'nda kısitların bir sistemin performansını belirlediği ve her sistemin muhakkak kısıtlara sahip olduğu ifade edilmektedir. Sistemin kısitına odaklanılarak sistemin tamaminda verimliliğin en üst düzeye optimize edilmesi amaçlamaktadır (Polito vd., 2006, s.44). Bu sebeple kuramın sistem odaklı bir süreç iyileştirme yönetim bilimi olduğu söylenebilir (Goldratt ve Cox , 2018).

Her sistemin bir varoluş amacı vardır. Sistemler varlıklarını sürdürebilmek için gelişmeli, daha iyiye ulaşmalıdır. Kısıtlar Kuramı, kendilerini oluşturan pek çok alt sisteme de sahip olabilecek olan sistemin amacına ulaşma noktasında önceliğin sistemin aksayan yönünü değiştirmeye değil; sistemin en temel amacına verilmesi gerektiğini ifade etmektedir. KK'nın temel felsefesi, sistemin amacının net bir şekilde ifade edilmesi ve bu amaca odaklanılmasının gerekliliğidir. KK, herhangi bir sistemin performansının artırılması aşamasında, sistemin performansını en çok engelleyen kısıtların bulunması, yönetilmesi ve ortadan kaldırılması yönünde oluşturulmuştur. Sistemin bir zincir olarak düşünüldüğü Kısıtlar Kuramı'nda, zincirin esneklik veya kapasite 
yönünden birbirinden farklı halkaların birleşmesinden meydana geldiğ $i$ belirtilmektedir. KK, en zayıf halka ve odaklanılması gereken nokta olarak gördüğü kısıttan her zincirde en az bir tane bulunduğunu ve sistemde yer alan en zayıf halkanın yani kisitın bir bütün olarak performansı etkilediğini ifade etmektedir. Bu kurama göre öncelikle en zayıf halkanın güçlendirilmesi için gerekli adımlar atılır ve bu kısıtın ortadan kaldırılması sağlanır ancak süreç tamamlanmaz ve bir başka halkanın en zayıf halka olarak sistem performansını etkilediği düşünülür. Bu durumda sistem dinamik bir hal alır. Dettmer (1997), sistemlerin en zayıf halkaları kadar güçlü olduğunu belirtmektedir. KK, her kısıtın bir ilerleme fırsatı olduğunu öne sürmüş ve kısıtları pozitif olarak değerlendirmiştir. Kısıtların belirli aşamalar halinde kaldırılmasının sistemin performansını arttıracağını savunur (Akman ve Karakoç, 2005, s.105). Ruhl (1995), Kısıtlar Kuramı'nın bir yönetim sistemi felsefesi olduğunu ve temel olarak kısıtların sistemin performansını belirlediğini ifade etmiştir. Her sistemde performansı olumsuz etkileyen en az bir kısıt olduğu vurgulanan Kısıtlar Kuramı'nda öncelik, kısıtın tanımlanmasıdır (Tollington, 1998).

Kisıtlar Kuramı sistemde verimliliği artırmakla kalmayıp rekabet avantajı da kazandırarak gelecek yatırımlar için yeni stratejilerin daha rahat belirlenmesine yardımcı olmaktadır (Chakravorty ve Atwater, 1994). Böylece yöneticiler mevcut uygulamaları neye, niye ve nasıl dönüştüreceklerine dair bilgiler edinirler.

Özetle Kısıtlar Kuramı, her sistemin bir amacı ve kısıtı olduğu bununla birlikte sistemin parçalarının toplamından daha büyük olduğu felsefesi üzerine kurulmuştur.

\section{Kısıtlar Kuramı Mantıksal Düşünme Bileşenleri}

Beş aşamalı odaklanma süreci: KK kısıtların belirlenmesinde ve yönetilmesinde tekrarlayan beş aşamalı bir süreçten oluşan beş odaklanma adımını kullanır (Goldratt ve Cox, 2018). Beş aşamalı odaklanma süreci, organizasyonu yöneten kişinin sistemde sürekli, kısıt arayıp bulması ve sistem üzerindeki etkisini azaltması ya da ortadan kaldırması işidir. KK için kabul edilen bu uygulama, mevcut 
paradigmalar ve sürekli iyileştirme yolundaki kısıtlamalar hakkında sorular sormaya yardımcı olmaya çalışır. Bu beş aşama sırasıyla şöyledir:

1. Sistemin kısıtının tanımlanması: KK'ında kısıtın tanımlanması, beş aşamalı odaklanma sürecinin birinci basamağıdır. Sistem kısıtının etkin şekilde yönetilmesi için öncelikle sistem kısıtının yani organizasyonda darboğazların belirlenmesi gereklidir. Teorik olarak, süreçte birbirini takip eden kaynakların kapasitelerinin hesaplanarak darboğaz kaynağının bulunmasıdır. Pratik olarak da örgütteki tecrübeli yöneticilerin ve diğer çalışanların darboğazları tespit etmeleridir. Bu kısım bize iyileştirme çabalarımızda nereye odaklanacağımızı söyler; çünkü belirlenen kısıt, organizasyonun hedefine ulaşmasındaki en önemli engeldir ve kısıtlamadaki bloklar tüm sistemin bloklarıdır. Sistemin verimliliğini artırmak için mevcut darboğazın hafifletilmesi gerekir. Böylelikle organizasyondaki en önemli kısıttaki bir iyileşme sistemde fark yaratacak ve sistem gelişecektir. Kısıtların doğru tanımlanması hedefe ulaşmada başarı sağlayacaktır. Öncelikle sistemin kısıtının fiziksel mi, ekonomik mi, yönetsel mi, politik mi olduğu; nerede ve neyden kaynaklandığı belirlenir ve kısıt net olarak ifade edilir.

2.Kısıtın nasıl çözüleceğine karar verilmesi:Bu adımda sistemin performansını artırmak için tanımlanan kısıtın nasıl çözüleceğine karar verilir. Kısıtın çözümüne yönelik olası tüm çalışmalar yapılır. Kısıtın en ekonomik ve en verimli şekilde nasıl aşılabileceği belirlenir. Ĕ̆er sistemde birden çok kısıt tespit edilmişse hangi kısıta öncelik verileceği belirlenir ve öncelik verilen kısıtın etkisini azaltmaya ya da ortadan kaldırmaya yönelik stratejiler geliştirilir. Temel darboğazlar keşfedildikten sonra sistemin debisini (throughput) yükseltmek için yollar bulunur. Bunun için darboğaz kaynağın kapasitesi (ek kaynak temin ederek, darboğazları geliştirerek vb.) artırılabilir. Sahip olunan kısıtın kapasitesini maksimize etmek, o kısıtı optimum düzeyde kullanmak ve üretkenliğini en üst düzeyde kullanmak için mümkün olan her şey yapılmalıdır. Başka bir deyişle, kısıtlama \% 100 kullanılmalıdır. Kısıtlama, organizasyonun hedefine ulaşmasında sistemin en yavaş veya en sınırlayıcı yönü olduğundan, kısıtlamanın en verimli kullanılmasını sağlamak verimi artırmanın ilk adımıdır. Yani 
kısıtlamadaki herhangi bir gelişme tüm sistemin çıtısını geliştirir. Bunun tam tersi olması durumunda ise tüm sistem yüksek performans harcasa dahi genel çıktıya etkisi olmayacağı için hedefe ulaşmak mümkün olmayacaktır.

Bunun için organizasyonu yönetenin;

- Diğer kısıtlar arasından en öncelikli kısıtı tespit etmesi,

- Kısıtı, organizasyonun en değerli varlığı olarak belirlemesi,

- Kisıt hakkında iyi analiz yapması,

- Çalışanlarından en iyi performansı alması gerekmektedir.

3. Diğer her şeyin kısıta göre belirlenmesi:Kısıtın nasıl çözüleceğine karar verdikten sonra sistemdeki diğer her şey buna göre tekrar ayarlanır. Bu aşamada kısıtı ortadan kaldıracak ve sistemin performansını artıracak tüm diğer çalışmaların sonuçları hesaplanır. Bu çalışmalar sistemin elverdiği mevcut durum çerçevesinde yapılan iyileştirmelerdir. Eğer belirlenen kısıt ortadan kalkar ise birinci aşamaya dönülür ve sistemin performansını etkileyen yeni kısıt aranır. Sonraki adımda yöntemler belirlendikten sonra her şey bu kararın doğru uygulanması için seferber edilmelidir. Sistemin performans ölçütleri bu kararın uygulanması ve başarısına göre düzenlenebilir. Böylece tüm çalışma yöntemi bu hedefe kilitlenmiş olur. Sistem için alınan tüm kararlarda, kısıtın nerede olduğunu bilmek ve buna dayanarak kararlar almak gerekmektedir. Diğer kısıtlama olmayanların görevi de alınan bu kararlara göre kısitlamanın gereksinimlerine tabi olmaktır.

4. Kısıtın önlenmesi: Sistemdeki her şey belirlenen kısıta göre ayarlandıktan sonra eğer kısıt çözülmüyor ise daha büyük değişikliklerin gerekliliği ortaya çıkar. Bu adımda daha fazla kaynak kullanmak gerekmektedir. Çünkü sistemde keşfedilmiş ve süreçleri iyileştirilmiş darboğazların belli bir süre sonra tamamen ya da kısmen ortadan kaldırılması gerekir. Bu durumda sistemde yeni darboğazlar türemiş olabilir. Önceki adımları tamamladıktan sonra kısıtlamanın kapasitesini artırmak ve böylece de sistemin performansını artırmak mantıklıdır. Kapasite eklemek, zaman ve para açısından çok pahalı olduğundan, bunun ilk çare olarak değil de son çare olarak yapılması; 
var olan kapasitenin organizasyonun imkanları içinde iyileştirilmesinin önceliklenmesi daha uygun görülmektedir.

5.1. adıma dönülmesi:Performans artırmaya yönelik uygulanan $K^{\prime} n ı n$ aşamaları doğrusal değildir. 3. ve 4. adımlarda kısıtın çözümü sağlandığında tekrar birinci adıma dönülerek sistemin performansını etkileyen yeni kıstllar belirlenir. $\mathrm{Bu}$ şekilde sistemde sürekli iyileştirmeler yapılır. Darboğazlar ortadan kaldırılmak istendikçe yenileri ortaya çıacaktır. Bunların her seferinde tespiti gittikçe zorlaşabilir. Ancak organizasyon atalete düşmeden değişime istekli olmak önemlidir. Sistemin verimini artırmak için sürekli yeni kısıtlama bulunmalı, diğer her şey yeni kısıta tabi tutulmalı ve ardından yeni kısıtlama da yükseltilmelidir.

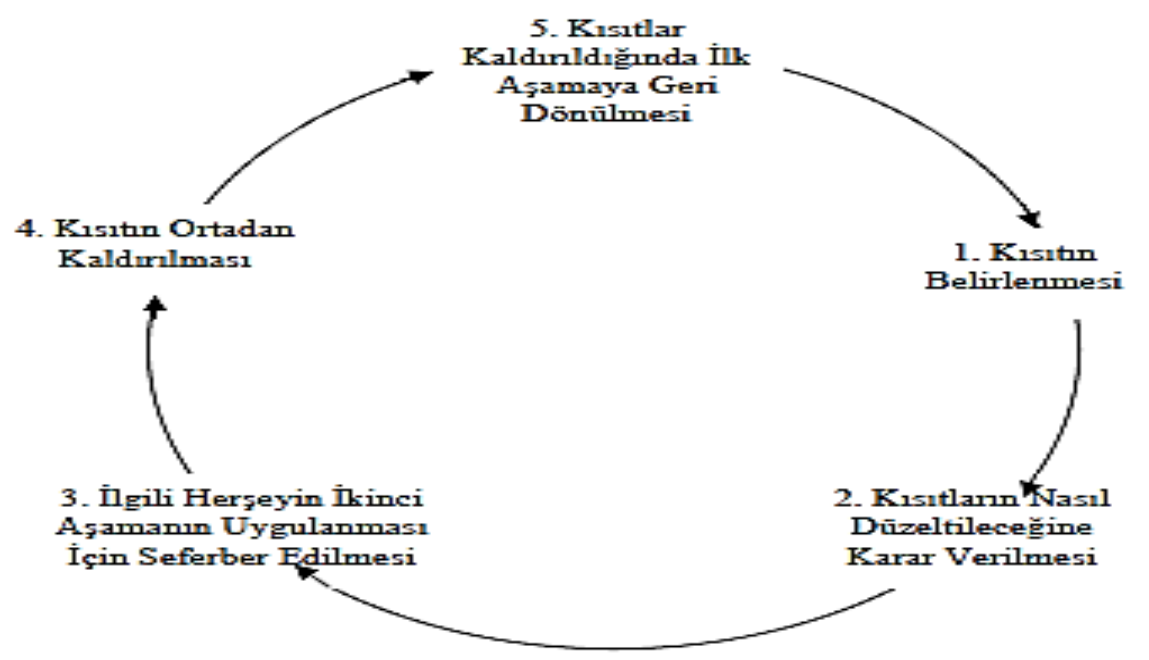

Şekil 1. Sürekli İyileştirme Süreci (Rahman,1998, s.336)

\section{Eğitimde Kısıtlar Kuramı}

Kısıtlar Kuramı, kısıtların sistemlerin performansını belirlediği ve her sistemin kısitlara sahip olduğu varsayımı üzerine kurulmuştur. Verimliliği en üst seviyeye çıkarmayı amaçlayan Kısıtlar Kuramı (Polito vd., 2006, s.44), bunun ancak sistemin kisitına odaklanma yoluyla elde 
edilebileceği temeline dayanır. Kısıtlar Kuramı, sistem odaklı bir süreç iyileştirme yönetim bilimi, şeklinde ifade edilmiştir (Goldratt ve Cox, 2018). Buradan hareketle Kisıtlar Kuramı felsefesinin eğitim sistemlerinin etkili ve verimli çalışabilmesi için eğitim alanında da uygulanabileceği savunulmaktadır (Suerken, 2013). Kısıtlar Kuramı'nın bir kişinin, kuruluşun veya sistemin amacına ulaşmasını engelleyen temel sınırlamaları mantıklı bir şekilde tanımlamak ve aşmak için kullanılan hem bir yöntembilim hem bir dizi düşünme süreci olarak eğitim kurumları açısından uygun bir kuram olduğu ifade edilmektedir (Suerken, 2013). Goldratt, eğitmenlerin Kısıtlar Kuramı'nı öğrenmesi ve uygulaması amacı ile "Eğitim İçin Kısıtlar Kuramı" isimli (TOCfE -TOC for Education) bir vakıf kurmuştur. 1995 yılında kurulan vakfın "Dünyayı Öğrenme ve Yaşam İçin Daha İyi Hale Getirme" misyonuna sahip olduğu bilinmektedir. TOC for Education, 6 kita 22 ülkede 250.000 'den fazla eğitimci tarafından kullanılırken 8 milyondan fazla öğrenciyi de etkilediği belirtilmiştir (tocforeducation.com).

Kisıtlar Teorisi ve mantıksal düşünme süreci yalnızca bileşenlerin parçalı gelişmelerini bir araya getirmekle kalmayıp, tüm sistemleri koordine etmek ve optimize etmek için yapılandırılmış bir çerçeve ve mantıklı bir metodolojidir (Dettmer, 1997). Buradan hareketle, TOCfE International'ın yönlendirmesi ile çocukların eğitim süreçlerine uyarlanan ve Goldratt'ın Düşünme Süreçleri (TP) aracilığı ile temel soruları cevaplamak üzerine kurulmuş olan bu sisteme özellikle destekleyici sosyal hizmetlere katılan kurumlarda ve özel eğitim gereksinimi duyan öğrencilerin rehabilitasyonunda başvurulmuş ve oldukça etkili sonuçlara ulaşıldığı görülmüştür. (tocforeducation.com).

\section{Sonuç}

Toplumda var olan bütün sosyal, kültürel kurum; olgu ve değerler bireyin eğitimini etkilese de bireyin eğitiminden sorumlu başlıca kurumlar olarak öğrencilerin eğitim gördüğü, somut uygulamaların yapıldığ1 yerler olan okullar gösterilmektedir (Varış, 1991). 21. yüzyılda okulların, bilgiyi üreten bir gençlik oluşturmada yetersiz kalmaları ve hızla değişen bilgi teknolojisinin, okulun bilgi aktarma işlevini üstlenmeye başlaması, okulların toplumun ihtiyaçlarını karşılayacak 
biçimde yeniden yapılandırılmaları gerektiği konusunu gündeme getirmektedir (Yalçınkaya, 2004). Çünkü okulun başarısı eğitim sisteminin başarısı olarak ifade edilmektedir (Başaran, 1982; Aytaç, 2000). Bununla beraber okul temel değişim birimi olarak kabul edilmekte ve eğitim sisteminde yeniliğin, okuldan başlatılmasının daha doğru olacağı belirtilmektedir (Bursalığlu, 1994). Bu nedenle okulların ve dolayısıyla eğitim sisteminin; çağın getirdiği yenilenme ve gelişime hızla adapte olabilmesi ve daha öteye geçerek çağı değiştirmesi, değişimi belirlemesi ve yönlendirmesi gerektiği ifade edilebilir.

Bahse konu taleplerden yola çıkılarak günümüz koşulları, bireyin ve toplumun talep ve beklentileri birlikte değerlendirildiğinde, Türk Milli Eğitim sisteminde yeni yönetim paradigmaları doğrultusunda okullarda uygulanabilecek performans geliştirmeye yönelik yeni bir modele ihtiyaç duyulduğu düşünülmektedir. Goldratt'ın (1990) ortaya koyduğu; herhangi bir sistemin performansının artırılmasında, sistemin performansını en çok etkileyen darboğaz unsurunun bulunması ve ortadan kaldırılması üzerine oluşturulmuş yönetim felsefesini içeren Kısıtlar Kuramı'nın eğitim sistemindeki okulların etkin bir şekilde yönetilmesi ve performansının artırılması için kullanılabilecek bir kuram olduğu söylenebilir (Suerken, 2013). Kısıtlar Kuramı (TOC), bir kişinin, grubun veya örgütün amacına ulaşmasını engelleyen temel sınırlamaları mantıksal olarak tanımlamak ve aşmak için kullanılan bir dizi düşünme sürecidir. Çoğu eğitimcinin her yaştan öğrenciyi şimdi ve gelecekte sorumlu ve üretken olmaya hazırlama hedefi vardır. Pek çok engel, bu hedefe ulaşmak için gereken iyileştirmeleri sınırlamaktadır. KK'nın bu engelleri aşmak için belirli araçları vardır. Buradan hareketle Türk Milli Eğitim Sisteminin okul öncesinden yükseköğretime kadar birçok örgün ve yaygın alt sistemden oluşan oldukça büyük bir yapı olduğu da göz önünde bulundurulduğunda, daha önce özel eğitim ve rehabilitasyona ihtiyaç duyan öğrencilerin eğitim aldıkları kurumlarda TOCfE işbirliği ile uygulanmış olan Kısıtlar Kuramı'nın hem okul gibi alt sistemlerde hem de sistemin tamamı için kullanılabilecek uygun bir kuram olduğu ve Türk Eğitim Sistemine entegre edilebileceği düşünülmektedir. 


\title{
EXTENDED ABSTRACT
}

\section{New Paradigms for Improving Performance in Education: An Evaluation in the Context of the Theory of Constraints}

\author{
Ercan Baysülen - Şefika Şule Erçetin \\ MONE- Hacettepe University
}

As societies become more complex and schools become more institutionalized, the educational experience has become more intricate with everyday life and with schools. This learning experience in a formal atmosphere is much more than what children can learn simply by observing, imitating or memorizing. This understanding has been instrumental in the society giving more importance to education and thus reformulating the general aims, content, organization and strategies of education. It can be said that these methods were created in line with the educational goals of the societies and the educational philosophy of that society. As a result, it seems to be a necessity to think about education with a "philosophical perspective" (Bircan, 2018).

Education is an initiative with certain goals and these goals vary according to the management and educational philosophies of the countries. The educational aims of the Republic of Turkey are expressed under two headings as general and special purposes in the Basic Law of National Education No. 1739. While general objectives cover abstract concepts such as being a good citizen and smart consumer, special objectives include knowledge, skills, attitudes and behaviors that are expected to be acquired by students at every school level.

School is a social system that is characterized by the work of individuals who are expected to achieve the goals of education and the way they interact with each other (Aydoğan and Pehlivan, 2002). Since the structure of this social system determines the functioning and quality of the process called education, the structure of school organizations has been a subject that is frequently emphasized together with the changes in the social structure. Education and school are in the field of interest of 
the institution with a number and number of people that cannot be seen in any other sector.

In recent years, developments in the field of information and technology in the world have directly affected other fields. One of the areas most affected by change is education. Educational institutions need to follow new understandings and developments in order to keep up with the changing age. Constructivist, applied and project-centered approaches have taken the place of traditional and rote-based learning in education (Teyfur, 2010). It can be said that the most important factor in increasing the quality, performance and quality of education is teachers. Teachers; accepted as one of the indispensable elements of education systems; The issue of training qualified teachers has formed an important aspect of education system reforms and success (Taşgin and Sönmez, 2013). In fact, all the factors in the system are of great importance in the realization of education and training activities. However, the teacher; It undertakes important tasks such as arranging the educational environment, ensuring coordination between the elements in the realization of education, choosing appropriate teaching methods, being successful in human relations and motivating students to learn. For this reason, it can be said that the role of the teacher is the most strategic and important role in the realization of educational goals (Taşgın and Sönmez, 2013).

The educational philosophy of societies expresses the type of people that society wants to raise and the design of society it wants to create. In line with this statement, it can be said that new ideas and different paradigms are needed to increase performance in schools, taking into account today's conditions, demands and expectations of the individual and society. From this point of view, it is considered important to conduct a research on how to increase the performance in educational institutions in the context of the Theory of Constraints. In summary, it is thought that analyzing an educational practice based on the Theory of Constraints will contribute to the field.

Theory of Constraints (TOC) It is a management philosophy put forward by Eliyahu Goldratt in the books "The Goal" and "The Race" in the 1980s and based on the understanding of identifying the bottlenecks of the system and eliminating them. In the Theory of Constraints, it is 
stated that constraints determine the performance of a system and that every system has constraints. Focusing on the constraint of the system, it is aimed to optimize the efficiency to the highest level in the entire system (Polito et al., 2006, p.44). For this reason, it can be said that the theory is a system-oriented process improvement management science (Goldratt and Cox , 2018).

Every system has a purpose of existence. Systems must evolve and achieve better in order to survive. The Theory of Constraints, the priority of the system, which may have many sub-systems that make up them, is not to change the failing aspect of the system; states that the system should be given its most basic purpose. The basic philosophy of KK is the necessity of expressing the purpose of the system clearly and focusing on this purpose. QC has been created to find, manage and eliminate the constraints that hinder the performance of the system the most during the stage of increasing the performance of any system. In the Theory of Constraints, where the system is considered as a chain, it is stated that the chain consists of the combination of different rings in terms of flexibility or capacity. KK states that there is at least one of the constraints that he sees as the weakest link and the point to be focused on, and that the weakest link in the system, namely the constraint, affects the performance as a whole. According to this theory, firstly, necessary steps are taken to strengthen the weakest link and this constraint is eliminated, but the process is not completed and it is thought that another link affects the system performance as the weakest link. In this case, the system becomes dynamic. Dettmer (1997), p.11-12) states that systems are only as strong as their weakest link. KK suggested that every constraint is an opportunity for progress and evaluated constraints positively. He argues that removing the constraints in certain stages will increase the performance of the system (Akman and Karakoç, 2005, p.105). Ruhl (1995) stated that the Theory of Constraints is a management system philosophy and basically constraints determine the performance of the system. In the Theory of Constraints, which emphasizes that there is at least one constraint that negatively affects performance in every system, the priority is to define the constraint (Tollington, 1998). 
The Theory of Constraints not only increases efficiency in the system, but also provides competitive advantage, helping to identify new strategies for future investments more easily (Chakravorty and Atwater, 1994). Thus, managers gain insight into what, why and how to transform existing practices.

In summary, the Theory of Constraints is based on the philosophy that every system has a purpose and constraint, and that the system is greater than the sum of its parts.

The aim of the study is to analyze the contribution of this theory to education within the framework of the principles put forward by the Theory of Constraints, based on the importance of education quality and performance in schools. Within the framework of this main purpose of the research, an evaluation will be made in terms of the applicability of the principles of the Theory of Constraints in education.

\section{Kaynakça / References}

Akman, G. and Karakoç, Ç. (2005). Yazılım geliştirme prosesinde kısıtlar teorisinin düşünce süreçlerinin kullanılması. İstanbul Ticaret Üniversitesi Fen Bilimleri Dergisi, 4(7), 103-122.

Akyüz, Y. (2011). Türk eğitim tarihi. Ankara: Pegem Akademi.

Aydoğan, İ. Y. ve Pehlivan A., İ. T. D. (2002). MEB ilköğretim okulları yönetici ve öğretmenlerinin personel geliştirmeye ilişkin görüşleri (Kayseri ili örneği) .Doctoral dissertation. Ankara Üniversitesi, Eğitim Bilimleri Enstitüsü, Eğitim Bilimleri Anabilim Dalı, Eğitim Yönetimi ve Planlaması Bilim Dalı, Ankara.

Aytaç, T. (2000). Okul merkezli yönetim. Ankara: Nobel.

Balc1, A. (1993). Etkili okul: Kuram, uygulama, ve araştırma. Ankara: Yavuz Dağıtım.

Başaran, İ. E. (1982). Örgütsel davranışın yönetimi. Ankara: Ankara Üniversitesi Eğitim Bilimleri Fakültesi Yayınları.

Bircan, H. H. (2018). Eğitim ve felsefe-eğitimin doğal/insanî, toplumsal ve felsefî temeli. Yüzüncü yıl üniversitesi sosyal bilimler enstitüsü dergisi, 40, 157-172.

Atwater, J.B. and Chakravorty (1994), Does protective capacity assist managers in competing along time-based dimensions? Production and Inventory Management Journal, 35. 
Bursalıoğlu, Z. (1994). Okul yönetiminde yeni yapı ve davranış, Ankara: Pegem Yayınları, 9. Basım.

Dettmer, W. H. (1997). Goldtratt's theory of constraints: A systems approach to continuous improvements. Wisconsin: Quality Press.

Dewey,J.(1939). Türkiye Maarifi hakkında rapor. İstanbul: Devlet Basımevi, s.38.

Erdoğan, İ. (2000). Okul yönetimi ve öğretim liderliği. Sistem yayıncılık.

Erşangur, C. (2003). İşletmede çalışanların performanslarını artırma ve performansların değerlendirmede katılıml yönetimin önemi ve Niğde sanayi işletmelerinde bir uygulama. (Yayınlanmamış Yüksek Lisans Tezi). Niğde Üniversitesi, Sosyal Bilimler Enstitüsü, Niğde.

Fidan N.,Erden, M. (1998). Ĕ̆itime giriş. İstanbul: Alkım Yayınları.

Goldratt, E. M. ve Cox, J. (2018). Amaç. (Çev. Ayşe Bilge Dicleli). İstanbul: Optimist Yayınları.

Goldratt, E. M. (1990). What is this thing called theory of constraints and how should it be implemented? Great Barrington: The Northern River Pres.

Güven, İ. (2018). Türk eğitim tarihi. Ankara: Pegem Akademi.

MEB, (2018). 2023 Eğitim vizyonu. Milli Eğitim Bakanlığı. 21.04.2021 tarihinde

http://2023vizyonu.meb.gov.tr/doc/2023_EGITIM_VIZYONU.pdf erişilmiştir.

MEB İlköğretim Kurumları Yönetmeliği. Resmi Gazete. 21.04.2021 tarihinde http://mevzuat.meb.gov.tr/dosyalar/1703.pdf erişilmiştir.

Milli Eğitim Bakanlığı Özel Eğitim Hizmetleri Yönetmeliği. Resmi Gazete. 21.04.2021 Tarihinde https://orgm.meb.gov.tr/alt sayfalar/mevzuat/Ozel Egitim Hizmetleri Yo netmeligi son.pdf indirilmiştir.

Milli Eğitim Temel Kanunu. 21.04.2021 tarihinde https://www.mevzuat.gov.tr/MevzuatMetin/1.5.1739.pdf indirilmiştir.

Ortaş Y. (2005). Senaryo tabanlı öğrenme yaklaşımına (stöy) dayalı eğitimde drama yönteminin, ilköğretim beşinci sınıf öğrencilerinin okuduğunu anlama başarılarına etkisi. Çukurova Üniversitesi Sosyal Bilimler Enstitüsü Dergisi, 14(2), 465-482.

Polito S. ve ark. (2006). Rekabetçiliği geliştirmek için kısıtlar teorisini kullanmak: bir havayolu vaka çalışması, rekabetçilik incelemesi Küresel Rekabetçilik Dergisi, s.44-52. 
Rahman, S. (1998). Theory of constraints: A review of the philosophy and its applications. International Journal of Operations \& Production Management, 18(4), 336-355.

Ruhl, Jack M. (1995). An introduction to the theory of constraints. Journal of Cost Management, 10(2), 43-48.

Suerken, K. (2013). TOC for Education. In F. Cox \& J.H. Schleier (Eds.), Theory of constraints handbook (p.787-812). McGraw-Hill.

Şişman, M. ve Turan, S. (2004). Bazı örgütsel değişkenler açısından çalışanların iş doyumu ve sosyal-duygusal yalnızlık düzeyleri (MEB şube müdür adayları üzerinde bir araştırma). Eskişehir Osmangazi Üniversitesi Sosyal Bilimler Dergisi, 5(1), 117-128.

Şişman, M. ve Taşdemir, İ. (2008). Türk eğitim sistemi ve okul yönetimi. Ankara: Pegem A Yayıncilık.

Taşgın, A. ve Sönmez, S. (2013). Öğretmenlik mesleği genel yeterliklerinin sınıf öğretmenleri ve sınıf öğretmeni adaylarının görüşlerine göre değerlendirilmesi. Middle Eastern \& African Journal of Educational Research, 3, 80-90.

Teyfur, E. (2010). Yapılandırmacı teoriye göre hazırlanmış bilgisayar destekli öğretimin 9. sınıf coğrafya dersinde öğrenci başarısı ve tutumuna etkisi. Ahi Evran Üniversitesi Kırşehir Eğitim Fakültesi Dergisi, 11(3), 85-106.

Tollington, T. (1998). ABC $v$ TOC same cloth as absorption $v$ marginal, different style and cut?. Management Accounting (CIMA), April, 76

Varış, F. (1991). Eğitim Bilimine Giriş. Ankara: A.Ü. Eğitim Fakültesi.

Yalçınkaya, M. (2004). Okul merkezli yönetim. Ege Eğitim Dergisi, 5(2), 21-34.

\section{Kaynakça Bilgisi / Citation Information}

Baysülen, E. ve Erçetin, Ş. Ş. (2021). Eğitimde performans artırmaya yönelik yeni paradigmalar: Kısıtlar Kuramı bağlamında bir değerlendirme. OPUS-Uluslararası Toplum Araştırmaları Dergisi, 18(44), 8455-8474. DOI: 10.26466/opus.969781 